\title{
Proof
}

\section{The impact of tourism on Latin American World Heritage towns}

\author{
Alfredo Conti
}

The origin of tourism in the modern world is directly linked to the construction of the concept of cultural heritage. From the 1980s onwards, World Heritage properties, considered the most important testimonies of monuments, groups of buildings and sites throughout mankind's history, have become main targets for tourism, especially historic towns and centres that express, sometimes more than other heritage categories, the features of a specific culture. Historic towns and centres constitute the main contribution, from a quantitative point of view, of Latin America and the Caribbean to the World Heritage List. These properties illustrate especially the colonial period, between the sixteenth and early nineteenth centuries, even if a few examples from the late nineteenth and twentieth century are also inscribed on the List. One of the main impacts of inscription on the World Heritage List is an increase in the number of visitors. Although tourism constitutes an opportunity for development, through financial benefits, the creation of jobs or the improvement of public spaces and urban infrastructure, threats to the values of the sites are also frequent, especially in those cases where no adequate planning exists. The conflict between the historic town and the tourism town becomes evident in several aspects: replacement of the traditional population in favour of new building owners, disappearance of traditional functions in favour of new services for visitors, unequal distribution of benefits and impact on traditional ways of life of local communities, who are sometimes subject to visitors' expectations. Even if tourism produces benefits, the lack of proper planning oriented to sustainable tourism causes several kinds of problems regarding authenticity and preservation of the outstanding universal values of these unique or exceptional towns. This chapter presents some common situations and explores the impacts on some specific cases of Latin American towns inscribed on the World Heritage List.

\section{The relationship between cultural heritage and tourism}

The origin of tourism in the modern world is closely linked to the recognition and 
Rome, to make direct contact with relics of classical antiquity. The ancient world, especially Roman civilization, had been 'rediscovered' by the culture of the Renaissance, and Rome had become a destination for those who wanted to know and appreciate classic art, which was taken as a source of inspiration for artistic production of the time (Choay 1992). This meant the implementation of infrastructure and equipment to meet the needs and requirements of the travellers, including transportation systems and accommodation, all of which constitutes the background to modern tourist facilities. This initial form of tourism included some components of its current definition: the idea of 'tour' meant that travellers returned to their places of residence once their expectations had been met; they were motivated by cultural purposes, and funds invested in the destination came from their home countries. In short, it was, in modern terms, a practice of cultural tourism, reserved for a select social group in terms of education and economic position.

The major economic, social and cultural changes brought about by industrialization all over the world led to new modalities of tourism; among the rights recognized for workers appeared, especially throughout the twentieth century, free time, holidays and leisure. New social groups were gradually incorporated into the practice of tourism. At the same time, new heritage items expanded the realm of tourism attractions, something that has occurred up to the present time. The interest in nature typical of the scientific field between the seventeenth and eighteenth centuries was transferred to the realm of art, especially by nineteenth-century Romanticism; the natural environment was considered as a source of contemplation and relaxation for body and spirit. The translation of this expansion of the concept of heritage impacted the field of tourism; besides sun and beach and cultural tourism, in our time several other modalities appeared, among them ecotourism and adventure, health, business, religious, gastronomic tourism, etc. Over the twentieth century, and particularly the period after the Second World War, progress in transportation and general improvements in revenues facilitated the access of new social groups to the possibility of travel. Social tourism emerged, which ensured the possibility of holidays for workers, and mass tourism, which has continued to expand, making tourism a top economic activity at the international level and, for many countries and regions, a source of economic growth and overall development of communities.

This qualitative and quantitative development of tourism as economic activity coincides with the extension of the concept of cultural heritage in the second half of the twentieth century. The initial idea of 'historic monuments', reserved for the great creations of humankind throughout history or the buildings and sites that had been the scene of memorable events, was changed, as expressed in the Venice Charter (1964), to include testimonies of a particular civilization, a significant development or a historic event, and the concept of monument referring not only to great works but also modest works that have gained cultural significance over time. This expansion of the concept of heritage implied the consideration of modest popular buildings, vernacular architecture, rural or industrial settlements, etc.

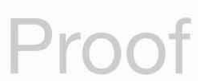


In the late twentieth century, new heritage categories were considered; in 1992, the United Nations Educational, Scientific and Cultural Organization (UNESCO) introduced the concept of cultural landscape, consisting of the joint work between man and nature. In 2005, the notion of heritage routes was included in the Operational Guidelines for the Implementation of the World Heritage Convention, which implies the consideration of heritage structures based on roads that played a specific role over a considerable period of time and served for cultural exchanges manifested in tangible and intangible heritage components. Moreover, intangible heritage, consisting of literary and musical traditions, social practices, oral history and traditional knowledge, gained significant ground in the theoretical debate and in the field of heritage management, manifested in the adoption by UNESCO of the Convention for the Safeguarding of Intangible Heritage of 2003. In this framework, historic towns and urban areas became one of the most significant heritage assets, since they express, perhaps better than other heritage categories, all the complexity of the human relationship with the environment, merging tangible and intangible heritage components. In this sense, historic towns and urban areas clearly express the idea of heritage as a symbolic reference to the cultural identity of the community (Prats 1997).

At the turn of the twenty-first century, new economic, social and cultural pressures posed new challenges for managing heritage assets. A detailed account of the social, political, economic and cultural conditions of the past two decades is a task beyond the scope and extent of this work, therefore only some aspects will be mentioned with the purpose of better understanding the situation in relation to impacts on heritage and its link with tourism. It is often said that the twentieth century ended between 1989 and 1991 with the fall of the Berlin Wall and the collapse of the Soviet Union. The end of the Cold War began a new period of 'globalization', whereby the different regions of the world are integrated into a single global capitalist market in which competition in pursuit of positioning has a key role. This process was accompanied by significant advances in information technology, notably the diffusion and use of the Internet, with the possibility of a world in permanent communication and connection. Furthermore, tourism underwent a significant expansion; most social groups are no longer satisfied with what is near in terms of distance, but look to expand their experiences in space and in time, both in real and virtual dimensions. As a counterbalance to globalization, the idea of 'local development' emerged, understood as integral growth and improvement, and not only in economic terms, based on the exploitation and utilization of the available resources for a given territory and the community that inhabits it. Against this background of counterpoint between global and local and competition to win markets and audiences, it is not surprising that countries and, in particular, some cities that have traditionally served as sources of generation and sharing of information have begun to look for a better positioning. This aspiration includes large or medium-sized cities, which seek ways to find a place in the global market, in the pages of the press or on the global virtual highway.

One of the key strategies of positioning is to provide cities with new equipment, usually intended for administration, culture, tourism and entertainment. These 
operations sometimes result in the revitalization of areas that were degraded or under-developed or comprehensive renovation activities; new urban areas are designed to meet the demands of contemporary life. Attracting visitors usually becomes a key strategy, taking into account the economic benefits involved. Heritage properties, especially urban areas or historic centres, are considered an economic resource capable of adapting, through new uses, to the requirements of present society while lending prestige, and act as a main attraction for tourism development. The World Heritage status of some sites implies a significant added value; inscription on the prestigious UNESCO List becomes a scaling factor, not only in strictly cultural terms but also economically, taking into account that the mere fact of registration acts as an efficient and powerful means of dissemination and promotion.

International governmental and non-governmental organizations involved in the conservation and protection of heritage work hard in seeking a balanced relationship between conservation of cultural and natural heritage and tourism use. Several international documents account for such concern. The United Nations Conference on International Travel and Tourism, held in Rome in 1963, stressed the importance of cultural and natural heritage for tourism, calling for conservation measures. In Latin America, the Norms of Quito (Organization of American States 1967), the final document of a meeting sponsored by the Organization of American States, established in 1967 that monuments should be considered as an economic resource, comparable to natural resources, and that their tourism use can be considered a source of development. The document warned, however, about the need for proper planning to ensure the correct tourism use of heritage, including contribution to conservation.

The International Council on Monuments and Sites (ICOMOS) adopted in 1976 an International Charter on Cultural Tourism. The extraordinary growth of tourism over the last decades of the twentieth century led ICOMOS to review the Charter; a new text was adopted in 1999 (ICOMOS 1999), more suitable to the demands of the moment. This text introduces concepts and recommendations related to the proper interpretation and transmission of heritage values and meanings, with the need to consider the tourism use of heritage as a tool for the comprehensive development of host communities through the idea of participatory planning involving all stakeholders.

\section{World Heritage towns}

As defined in Annex 3 of the Operational Guidelines for the implementation of the World Heritage Convention (UNESCO 2008), historic towns and urban areas constitute, in quantitative terms, the most significant contribution of Latin America and the Caribbean to the World Heritage List. Some 40 per cent of the cultural sites inscribed on the List and located in this region belong to this heritage category, which represents, at the same time, some 31 per cent of the total number of sites inscribed. Most World Heritage historic towns or urban areas belong to the colonial period (fifteenth to early nineteenth centuries), in some cases with a preHispanic background, such as Mexico City or Cusco; Brasilia constitutes an

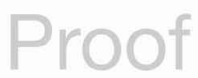


exceptional case of a World Heritage city of the twentieth century. If we consider that archaeological sites comprise the next biggest category, in quantitative terms, and that most of them correspond to pre-European towns in the Americas, we can conclude that the urban history of the continent is quite well represented on the List, much better than other heritage categories, such as cultural landscapes or monuments.

The inscription of historic towns or urban areas on the World Heritage List has an impact that can be defined and measured in terms of different aspects, with some positive and negative effects for their proper conservation in the framework of an integrated approach that takes into account not only economic aspects but also social ones, in particular those related to the quality of life of local populations. It is well known that World Heritage Sites are usually subject to economic and social pressure, for which the theoretical and operational instruments do not always appear to be adequate. In this sense, the debate started in 2005, with the introduction of the concept of 'historic urban landscapes', tends to update approaches and methodologies to deal with these sites.

Latin American World Heritage towns present common features when compared with others located in different geo-cultural regions but, at the same time, some specificities related to their history, morphology, architectural components and social and symbolic characteristics. At the same time, some particular pressures and requirements are evident. The construction of large cultural, administrative or entertainment complexes, currently common in several World Heritage towns all over the world, does not appear, for the time being, as a real threat in Latin America. On the other hand, the strong impact of tourism, social changes, the lack of adequate maintenance of public spaces and buildings and sanitation problems, which are not common problems in other regions, appear frequently in Latin America as a real threat to the integrity and authenticity of the World Heritage towns.

Some World Heritage towns underwent, over the nineteenth and twentieth centuries, a sometimes explosive extension and densification, since they are capital cities or important economic centres; others, in contrast, have had no major modifications to their original size and relations with the natural environment, in some cases on account of economic and demographic stagnation or their isolation with regard to the main productive or exchange circuits. In the first case, historic centres underwent a process that was in a sense similar to that of European cities: the original nucleus preserved their morphologic features and townscape and their function of institutional core of the city, and new urban areas absorbed the functional complexity implied by modernization. These historic centres underwent, in general, processes of substitution of population, becoming sometimes areas that lacked adequate infrastructure, offering bad living conditions and generating social marginalization and functional and physical degradation.

\section{Positive impact of tourism}

It is possible to define some indicators of what could be considered the positive impact of tourism on the heritage sites and on the local community. The general 
idea is that tourism constitutes an opportunity for development, and particular indicators are:

- $\quad$ economic benefits produced by tourism;

- creation of jobs related to tourism;

- improvement of infrastructure and public spaces;

- opportunities for education and training.

With regard to public spaces and infrastructure, World Heritage towns and urban areas are usually a target for improvement and enhancement. Often public spaces are well preserved and maintained; adequate urban furniture and infrastructure are provided or improved. This contributes to a general amelioration of the quality of life of the local population and enhances the experience of visitors.

Inscription on the World Heritage List and the associated increase in the number of visitors constitute an opportunity to restore historic buildings. New uses are often related to tourism. It is quite common in Latin American towns for old onefamily houses, which are quite difficult to continue in their original use, to be converted into accommodation for visitors. This can be considered an opportunity in two senses. On the one hand, historic buildings are restored and given a new use, generally by private investors, and, on the other hand, visitors may live the experience of lodging in typical historic houses, which is a means for deeper contact with the local culture.

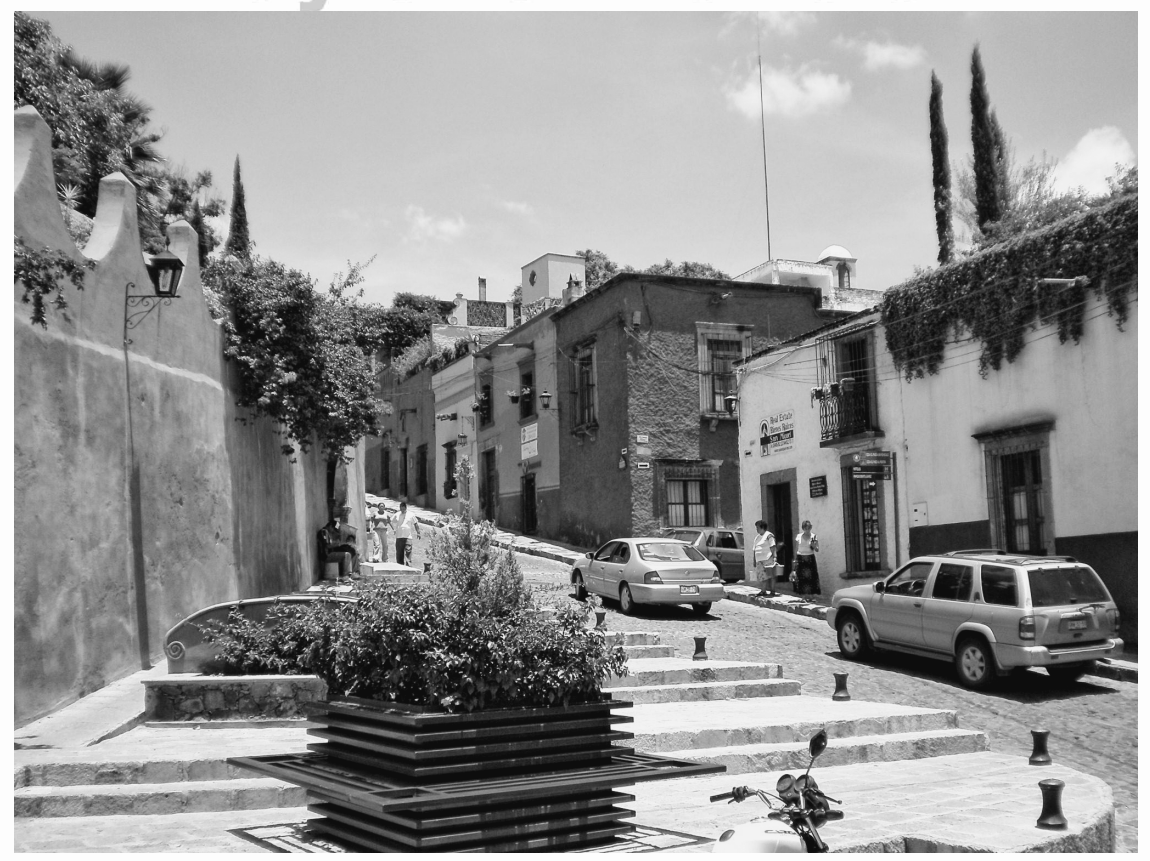

Figure 16.1 San Miguel de Allende, Mexico. The improvement of public spaces. 


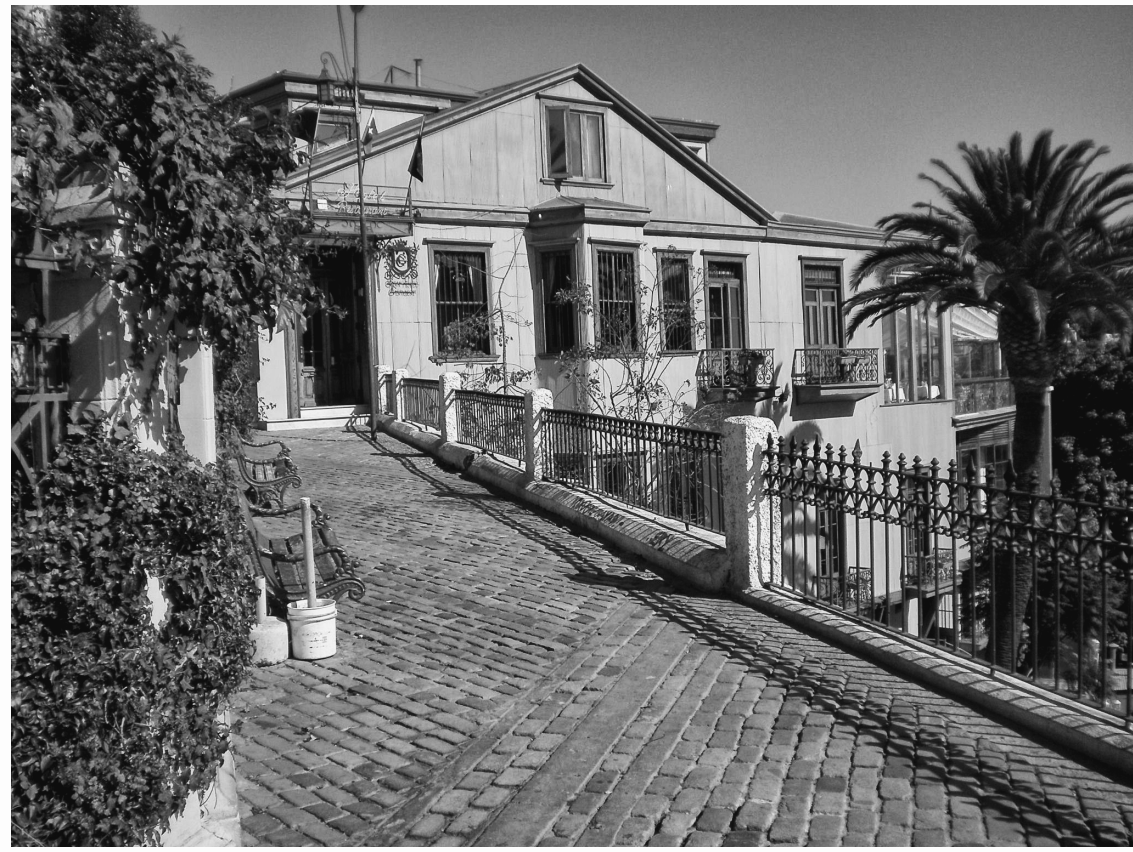

Figure 16.2 Valparaíso, Chile. Historic building transformed into a hotel.

Threats caused by tourism

Inscription on the World Heritage List and the tourism use of a town implies undoubtedly some opportunities for local development. But threats usually emerge, especially if no adequate planning has been done and implemented. In this sense, we can notice some differences between Latin American towns and those belonging to other regions of the world: since tourism is considered primarily a source of financial revenues, policies focus on promoting economic benefit and there is no balance with social or environmental aspects. Some of the threats to be discussed in detail are replacement of the traditional population, gentrification, threats to the authenticity of the sites and the impact on traditional ways of life.

\section{Replacement of the traditional population, gentrification}

A frequent aspect related to the management of historic urban areas and their historic neighbourhoods. This phenomenon is strongly linked to a process that can be noted equally in developed and underdeveloped countries. The inscription 
population. Traditional inhabitants of many historic areas are sometimes displaced by self-decision since they prefer to sell their houses and buy new ones outside heritage areas, something that produces financial benefit. In other cases, they are 'pushed' by the pressure of investors or by groups with major revenues that desire to buy properties in the prestigious historic areas.

The phenomenon of gentrification means the replacement of the typical population of a given urban neighbourhood with another population of greater financial resources or more exalted social position. The truth is that this process takes place in urban centres around the world, though with higher incidence in economically disadvantaged countries. The reason for this process lies primarily in the fact that the buildings are purchased by individuals or entities, usually turning them to different uses from those of the original. Thus, it is common to find old homes converted into hotels, restaurants or shops or even maintaining a residential use but occupied as secondary homes for short periods throughout the year. This means that the neighbourhoods gradually lose their population, which leads at the same time to a crisis regarding some aspects of authenticity. In this case, although the tangible components of the buildings may be in a good condition, or even improved with respect to their previous state, a loss of authenticity of function emerges.

\section{Threats to authenticity}

With respect to the alteration or distortion of heritage values and message, it is necessary to consider heritage as a set of tangible assets to which values related to history, art or science are assigned. In this sense, heritage is a carrier of meanings that we try to transmit, through the conservation of the material substance, from one generation to another. The proper understanding and interpretation of such values are therefore essential in order to comprehend the true meaning of heritage, to ensure proper its use and to preserve its authenticity, understood not only as the preservation of the tangible components but also the intangible ones such as functions, vocations, associated traditions, etc. In this sense, a conflict often observed with the spread of mass tourism is that heritage becomes a sort of spectacle and object of consumption, without achieving the adequate transmission and understanding of its values.

It may happen that while a heritage site is well preserved and its carrying capacity or limits of change are maintained at appropriate levels, its dedication to tourism involves risks to its authenticity. This is a situation frequently observed in some heritage categories such as historic centres or urban areas. According to current theory, authenticity is verified in several ways, taking into account tangible and intangible components; thus authenticity includes the consideration of materials, shape and design, setting, functions and vocations, meanings and traditions associated with specific sites.

When we refer to threats to authenticity, we refer not only to damage that can occur to the material components of heritage but also to the risks posed to the intangible aspects that influence authenticity. Thus many historic towns or centres

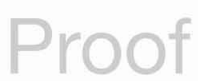


are very well preserved; both buildings and public spaces have good and proper maintenance. But excessive devotion to tourism means that the entire neighbourhood is devoted to visitors; all business is dedicated to the tourist, the old residences are now hotels or devoted to gastronomic uses, etc. The problem then is that while the material substance may be well preserved, the area has lost or drastically changed its meaning and its original functions, so there are aspects of authenticity that are really at risk. This tends to be one of the most complicated issues in the management of heritage sites.

\section{Impact on traditional ways of life}

Another type of impact is related to social aspects and, especially, to the relationship between the local community and visitors. Particularly when there is an economic asymmetry between them (more specifically in the case of tourism in economically disadvantaged regions), it is common for residents to consider visitors as an 'opportunity' to secure or increase their income. This can include the selling of typical products or the adoption of behaviours that are expected to have an impact on the visitor. It is common to find people who dress or act in a way that is not part of their daily lives; they become part of the stereotypical image of the site and, therefore, something that the tourist expects to see. The problem is that in this way the resident community, or some of its members, are at the service of visitors' expectations; this is another manifestation of the threat to authenticity, in this case lifestyles, habits, behaviours, etc.

Intangible heritage is fundamental not only to determining the outstanding universal value but also to the authenticity of World Heritage properties. In spite of problems of depopulation and gentrification, most Latin American World Heritage towns retain a very rich intangible heritage made up of, among other components, music, gastronomy and traditions. This intangible heritage is also a tourist attraction and could be jeopardized if adequate safeguarding measures are not defined and implemented. The question is what the limit is to safeguard traditional ways of life or social practices so that they can be preserved as authentic cultural manifestations and not as performances for visitors. What usually happens is that members of the local population act in the way visitors expect them to. There is a sort of alienation of the local population in the expectations of visitors; this is one of the most important threats to authenticity.

Within the social aspects some 'contradictions' appear between what could be called a positive effect on tourism and reality. When talking about tourism opportunities, we have referred to the economic benefit, to the possibility of improving urban spaces and to the provision of infrastructure and equipment. Often the economic benefit is not evenly distributed among the resident community; although there is a general improvement in the urban space and infrastructure, some sites are inaccessible to the residents. Many times the costs of access to cultural facilities and entertainment are fixed in terms of tourism, making them inaccessible to local people. 


\section{Some specific cases}

In order to illustrate some threats, a few examples of Latin American World Heritage towns and urban areas will be presented. This selection is not intended as criticism of those cases, but they are good examples of the opportunities and threats of tourism in World Heritage towns.

The first case is Cartagena de Indias, in Colombia, inscribed on the World Heritage List in 1984, one of the most beautiful and well preserved historic centres in Latin America. Some of the effects mentioned above can be clearly noticed in the historic centre, such as the improvement in the general condition of the public spaces and the possibilities of new uses for historic buildings. There are different areas within the historic centre. Those which exhibit the best state of conservation correspond to the Cathedral neighbourhood; the state of conservation of the public spaces and buildings is quite good, but the area has undergone a process of depopulation in favour of dedicating buildings to tourism services. Several historic houses have been restored, and very well restored, but they are occupied by people who use them as a second home. This means that these buildings are occupied only during holiday periods or weekends, being closed the rest of the year.

On the other hand, there are the areas where the pressures of tourism are not so evident as yet, where the traditional local population still lives. In the case of Cartagena, the neighbourhood of Getsemaní is the place of residence of the

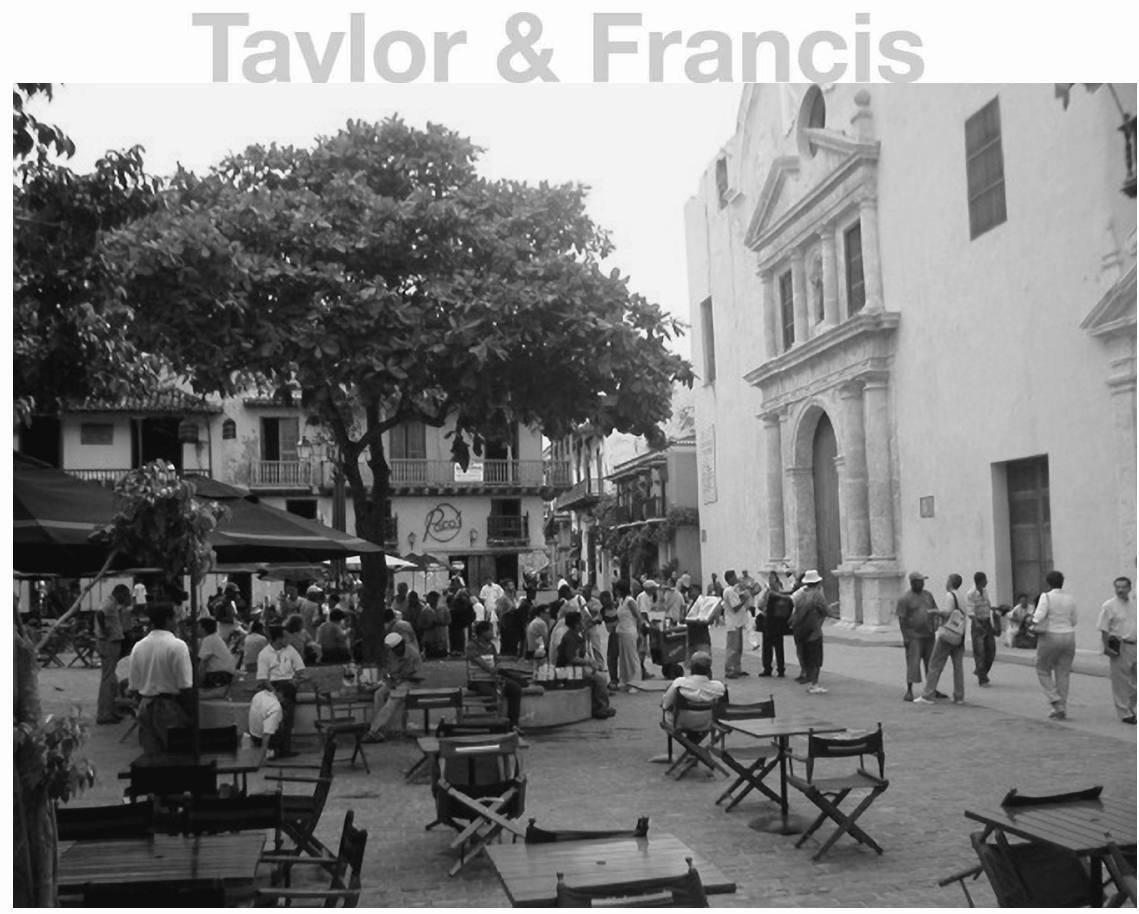

Figure 16.3 Cartagena, Colombia. Good state of conservation of public spaces and buildings in the historic centre.

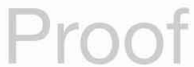




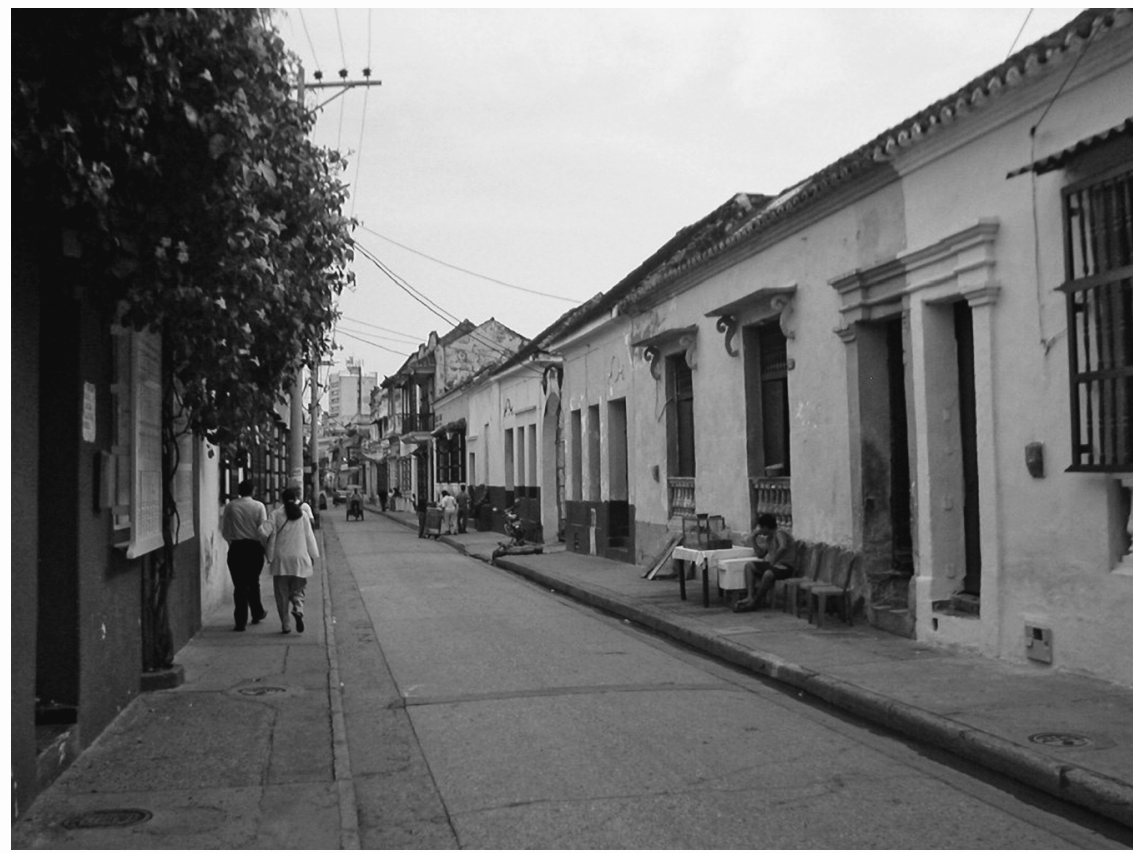

Figure 16.4 Cartagena, Colombia. Getsemaní neighbourhood. Popular housing retaining traditional ways of life.

low-income traditional population. Although the state of conservation of the

Another interesting example is the city of Colonia del Sacramento in Uruguay, whose historic centre was inscribed on the World Heritage List in 1995. This is an interesting example of the merging of different urban and architectural features, since the village was established by the Portuguese at the end of the seventeenth century and passed definitively to Spain at the end of the eighteenth century. Although there are no impressive architectural monuments, the historic centre retains much of the typical atmosphere of a colonial town, amplified by the setting of the historic centre on a peninsula by the Plata River. century, 330 inhabitants lived in the historic centre; at the same time, one and a half million visitors arrived in Colonia in 2008. It is worth mentioning that the town is located some two hours by car from Montevideo, the capital city of Uruguay, and 50 minutes by boat from Buenos Aires, the capital city of Argentina, with a population of some 10 million inhabitants and an important international 


\section{Proof}

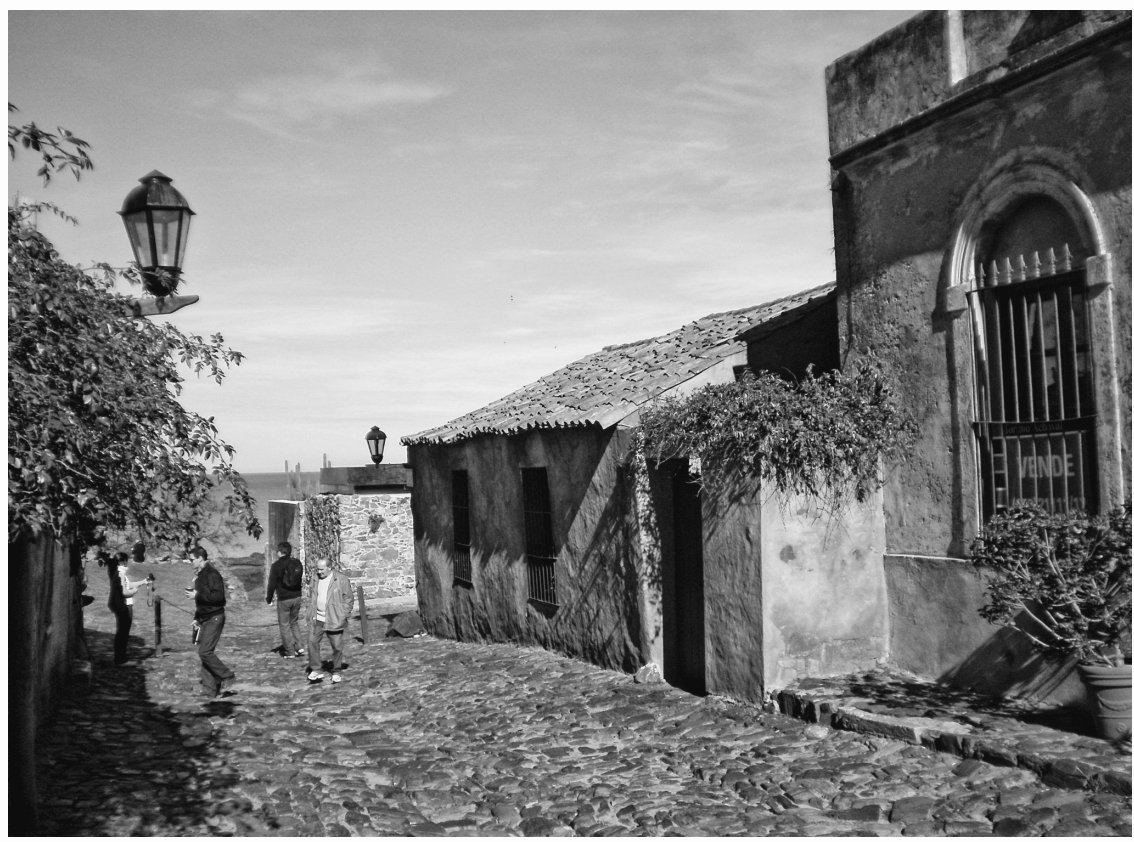

Figure 16.5 Colonia, Uruguay. Typical colonial atmosphere next to the Plata River.

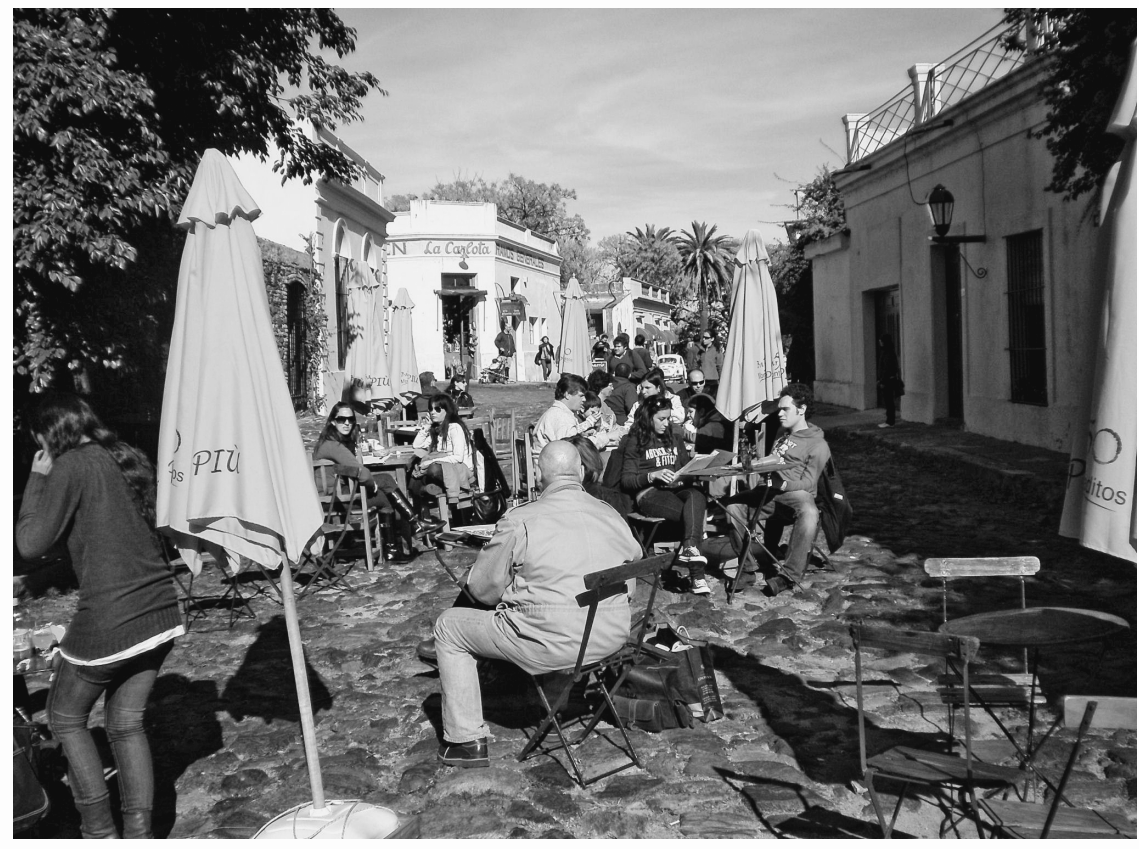

Figure 16.6 Colonia, Uruguay. Street space used for restaurants and cafés. 
tourism destination. Visits to Colonia are usually one day excursions from Buenos Aires, and this has a significant impact on the town.

Public spaces and architectural heritage are very well preserved in Colonia, and the local government makes significant investment in conservation and maintenance. The impact of tourism on the public space is noticeable; some streets have been closed to traffic and have become outdoor cafés or restaurants. Gentrification is also important in this town. Due to the increase in the price of plots and buildings, traditional inhabitants preferred to sell their houses in the historic centre and move to other neighbourhoods, with a significant economic benefit. Houses in the historic centre have generally been bought by foreigners who use them as secondary residences. In other cases, buildings have been devoted to new uses related to tourism, such as shops or diverse types of lodging facilities.

\section{Conclusion}

The necessity of fostering sustainable tourism becomes a must in these types of site since they bear outstanding universal values which make them unique or exceptional properties that deserve to be preserved in the full richness of their authenticity. World Heritage towns or historic centres act as significant tourism attractions; it is necessary to define and implement measures that prevent such sites from becoming only a beautiful place for tourism, something that could lead to prioritization of the expectations and desires of visitors to the detriment of local communities.

In the postgraduate course on heritage and sustainable tourism delivered at the UNESCO Chair on Cultural Tourism, Argentina, focus is placed on some aspects that could be mentioned as possible recommendations for action:

- financial benefits equally distributed; $\quad 29$

- $\quad$ respect for traditional ways of life; 30

- respect for the authenticity of tangible and intangible heritage components;

- balance between the needs of visitors and those of local communities. 32

These could help to achieve a healthy balance between the two aspects that characterize World Heritage towns: they are precious testimonies related to specific geo-cultural contexts but, at the same time, spaces for the everyday life of living communities.

Borié, A. and Denieul, F. (n.d.) Méthode d'analyse morphologique des tissus urbains traditionnels, Paris: UNESCO, Etudes et documents sur le patrimoine culturel (3). 
Conti, A. and Cravero Igarza, S. (2010) 'Patrimonio, comunidad local y turismo: la necesidad de planificación para el desarrollo sostenible,' Notas en Turismo y Economía, 1, La Plata: Facultad de Ciencias Económicas, Universidad Nacional de La Plata. Online, www.econo.unlp.edu.ar/notastye (accessed 1 June 2010).

ICOMOS (1993) Tourism at World Heritage Cultural Sites: The Site Manager's Handbook, Colombo: ICOMOS.

(1994) Nara Document on Authenticity. Online, www.icomos.org (accessed 15 October 2008).

(1999) International Charter on Cultural Tourism. Online, www.icomos.org (accessed 15 October 2008).

ICOMOS and Grupo de trabajo de países Iberoamericanos (2007) 'Foro sobre ciudades históricas y paisaje histórico urbano.' Unpublished paper.

Organization of American States (1967) Norms of Quito. Online, www.icomos.org/ (accessed 20 May 2009).

Organization of World Heritage Cities (2005) 'Conclusions of the 8th Congress of OWHC, Cuzco.' Unpublished document.

Prats, L. (1997) Antropología y patrimonio, Barcelona: Ariel.

Treserras Juan. J. (2005) 'El patrimonio como generador de desarrollo a partir del turismo.' Online, www.fundacioabertis.org/rcs_jor (accessed 20 May 2009).

UNESCO, World Heritage Centre (2007) 'Information Document by the World Heritage Centre on the Development of a Revised UNESCO Recommendation on the Conservation of Historic Urban Landscapes.' Working paper, unpublished.

UNESCO, World Heritage Committee (2008) Operational Guidelines for the Implementation of the World Heritage Convention. Online, http://whc.UNESCO.org/ (accessed 20 May 2009).

Van Hoff, H. (2004) El estado del Patrimonio Mundial en América y el Caribe. Informe Periódico 2004, Montevideo: Oficina UNESCO Montevideo. 